\title{
Geografia-geografias: a literatura (felizmente) se ocupa do que a historiografia parece menosprezar
}

\author{
Geography-geographies: literature (fortunately) dedicates to what \\ historiography seems to disregard \\ Antonio Carlos Hohlfeldt \\ Pontifícia Universidade Católica do Rio Grande do Sul/CNPq - Porto Alegre - Rio Grande do Sul - Brasil \\ Ana Cláudia Munari \\ Universidade de Santa Cruz do Sul - Santa Cruz do Sul - Rio Grande do Sul - Brasil
}

$\diamond$

\begin{abstract}
Resumo: O lançamento, em 1935, de uma narrativa histórica, denominada Noite de reis, recentemente reeditada, abre a oportunidade para uma revisão a respeito da chamada geografia literária do Rio Grande do Sul. Aquele texto, de autoria de Manoel Estevão Fernandes Bastos, praticamente inédito nos círculos literários sul-rio-grandenses ainda hoje, introduziu duas novidades no mapa literário do estado: a região geográfica das encostas da Serra Geral e da Serra do Mar, historicamente importante para a colonização e a ocupação dos territórios sulrio-grandenses, e o tipo humano ali presente, mescla de descendentes vicentinos e lagunenses com brasileiros do norte e colonizadores alemães. Para além desses aspectos, contudo, o texto é interessante exemplo de uma narrativa épica e ao mesmo tempo trágica, que mistura fatos históricos e ficção, sugerindo veios ainda não explorados para a literatura do estado sulino.
\end{abstract}

Palavras-chave: Literatura sul-riograndense; Crítica literária; Noite de reis; Fernandes Bastos

\begin{abstract}
The 1935 release of the recently re-edited historical narrative named Noite de reis makes way to a reconsideration concerning the so-called literary geography of Rio Grande do Sul. The text by Manoel Estevão Fernandes Bastos, practically unknown in literary circles of Rio Grande do Sul even today, introduced two innovations in the literary ambit of the state: the geographic region of Serra Geral and Serrra do Mar, which was historically important in colonization and occupation of Rio Grande do Sul's territories, and the human character who lived there and who was a mixture of Vincentian descendants and people from the city of Laguna with northeastern Brazilians and German colonizers. Moreover, the text is also an interesting example of a narrative that is both epical and tragic, merging historical facts and fiction, therefore suggesting paths that had not been explored the literature produced in Rio Grande do Sul.
\end{abstract}

Keywords: Literature from Rio Grande do Sul; Literary criticismo; Noite de reis; Fernandes Bastos

O Tratado de Tordesilhas, firmado entre Portugal e Espanha, em 1494, deixava fora do controle lusitano toda a imensa parcela de território abaixo do ponto hoje conhecido como Laguna, na América do Sul, pois o traçado determinado pelo documento indicava que os territórios à esquerda daquela linha imaginária seriam espanhóis. A coroa portuguesa pareceu ter admitido essa hipótese apenas como ponto de solução de uma grande e antiga disputa. Sabe-se, contudo, que Portugal e Espanha continuariam se digladiando ao longo dos próximos dois séculos, com vantagens, ora de um, ora de outro, em torno dessas geografias.
Na prática, Portugal deu pouca atenção ao território americano nas três primeiras décadas do século XVI, mais interessado nos lucros auferidos pelo comércio de especiarias, desde a longínqua Ásia e, logo depois, com o tráfico de escravos. Neste sentido, o arquipélago do Cabo Verde logo se revelaria estratégico, motivo pelo qual seus colonizadores receberam direitos de comércio incomuns para as colônias lusitanas (cf. HOHLFELDT; TARRAGÔ, 2011). Esse distanciamento, contudo, mudaria com a designação de um primeiro Governador Geral, em 1530, como se sabe, na pessoa de Martim Afonso de Sousa. Foi ele quem, naquela viagem, criou a 
vila de São Vicente ${ }^{1}$ e, enviando seu irmão Pero Lopes até as terras mais ao sul do continente, propiciou o primeiro registro documentado de que se tem notícia a respeito da atual costa do Rio Grande do Sul, considerada pelo viajante como um cemitério de navios (cf. SOUZA, 1979).

Foi Martim Afonso também quem construiu o primeiro engenho de açúcar no território paulista, ampliando a segunda alternativa de exploração econômica colonial, já experimentada no nordeste brasileiro. Para além do produto natural, que era o pau-brasil, implantavase agora e se desenvolvia uma atividade produtiva até então inexistente naquela colônia, a cana de açúcar. Ela viria a se tornar um dos mais lucrativos negócios para a metrópole e que responderia, em futuro imediato, pela abertura das rotas de tráfico negreiro para garantir a mão de obra necessária para fazer os engenhos produzirem lucrativamente.

É de São Vicente que partem os primeiros aventureiros a se arriscar, pelo mar ou pelo próprio continente, no desbravamento daquelas terras desconhecidas, ocupadas por gentios bastante conscientes de suas posses e que não viam com bons olhos a presença de estrangeiros entre si. Já em 1680 os portugueses haviam fundado a Colônia do Sacramento, no outro lado do rio da Prata, bem em frente a Buenos Aires. E em 1684, um grupo de vicentinos, liderados pelo capitão Domingos de Brito Peixoto, chega ao local hoje denominado Laguna e ali se estabelece, fundando pequeno aldeamento. Laguna torna-se, assim, ponto de chegada e de partida para novos empreendimentos. São os vicentinos - e agora os seus descendentes, chamados lagunenses, liderados por Francisco de Brito Peixoto, filho do fundador de Laguna - que começam a explorar a região, primeiro a litorânea, na direção do sul, rica em peixes e crustáceos, ao mesmo tempo em que desenvolvem a extração do sal. Brito Peixoto recebe, em 1721, a patente de guardamor, iniciando a descida para o sul, a partir de 1725 . Naquele ano, um grupo de 31 lagunenses, chefiados por João Magalhães, ultrapassa o rio Mampituba, de sorte que, por volta de 1730 , já temos bastante documentada a existência de outras localidades ao longo do território hoje sul-rio-grandense. A coroa portuguesa começa a distribuir sesmarias aos tropeiros que, tendo reunido alguns cabedais com o comércio de tropas e de couros, haviam decidido se estabelecer naquelas terras ${ }^{2}$. Em 1807, Portugal emancipa a região e a transforma na CapitaniaGeral de São Pedro (cf. CÉSAR, 1970).

Num movimento diverso, os padres jesuítas, expulsos da região do Guará Mirim (atual Mato Grosso), pelo bandeirante Antonio Raposo Tavares ${ }^{3}$, haviam descido o rio Paraná e, distribuindo-se à direita e à esquerda daquele rio, fundaram novas aldeias nos atuais territórios argentino e brasileiro, a partir de $1624^{4}$. Fixados na nova região, ali os jesuítas desenvolvem seus aldeamentos e, do mesmo modo que Hernando Aires de Saavedra tê-loia feito, como governador da Província do Rio de Prata, a partir de 1603, na região de Buenos Aires, também eles introduzem, nos Sete Povos, o gado vacum que, solto, reproduzir-se-á livremente, ocupando crescentemente toda a região do planalto, na direção do leste, constituindo o que, mais tarde, será denominado de "vacarias del mar", que alcançarão o atual território de Vacaria (no Rio Grande do Sul) e dali espalhando-se para a região de Lages (na atual Santa Catarina) (cf. PESAVENTO, 1985).

$\mathrm{O}$ encontro e os interesses desses dois grupos, aparentemente tão opostos, mas ao mesmo tempo complementares, permite o desenvolvimento da região a partir de um comércio relativamente incipiente, mas constante e crescentemente alargado: do planalto desce a carne e seus produtos derivados, como as gorduras. Da orla marítima sobem o sal e todos aqueles produtos inexistentes nas terras altas, sobretudo alguns materiais importados, que interessavam aos moradores do interior. Apesar do imenso desnível existente entre o planalto e a orla, que chega perto dos mil metros de altura, abrem-se picadas por onde muleiros sobem e descem a perigosa serra, traficando suas mercadorias.

A coroa portuguesa e os colonizadores lusitanos, já sediados mais ao sul daqueles territórios, ocupando as cercanias da Lagoa dos Patos e Mirim, assim como o forte da Colônia de Sacramento, logo se dão conta da importância estratégica e econômica da região e decidem ocupá-la mais efetivamente. É assim que Cristóvão Pereira de $\mathrm{Abreu}^{5}$, após inúmeras e infrutíferas tentativas, abre efetivamente um caminho que sai da Colônia e segue até Sorocaba, primeiro cortando o território da Província de São Pedro do Sul, na direção do nordeste, aproveitando a platitude da região, desde a já mencionada Colônia do

\footnotetext{
Embora a aglomeração existisse antes da chegada de Martim Afonso, a vila de São Vicente foi formalmente fundada a 22 de janeiro de 1532.

2 Ler, a respeito, PESAVENTO, Sandra Jatahy. História do Rio Grande do Sul. Porto Alegre: Mercado Aberto, 1985. Ver, em especial, p. 13 e seguintes.

3 O dramaturgo inglês Robert Bolt ocupa-se do tema, em $A$ missão, roteiro filmado pelo cineasta Rolland Joffé, em 1986. Neste trabalho, os bandidos são os portugueses, que dizimam as missões jesuíticas.

$4 \mathrm{O}$ escritor pelotense João Simões Lopes Neto mitifica o tema através da lenda "A salamanca do jarau", conforme Antonio Hohlfeldt estudou detalhadamente em Ficção e realidade (Rio de Janeiro: Antares 1982, especialmente p. 45 e seguintes.) e, posteriormente, em Literatura e vida social (Porto Alegre: EDUFRGS, 1996 especialmente p. 35 e seguintes.). No texto, procura-se evidenciar a transformação do episódio histórico em referência mítica fundadora da civilização sul-rio-grandense. A mesma perspectiva é parcialmente desenvolvida por Flávio Loureiro Chaves, em Simões Lopes Neto: Regionalismo \& literatura (Porto Alegre: Mercado Aberto, 1982) e mais decididamente por Lygia Chiappini Leite, em No entretanto dos tempos: Literatura e história em João Simões Lopes Neto (São Paulo: Martins Fontes, 1988).

5 Ver, especialmente, o romance $O$ cavaleiro da Terra de Ninguém, de Sinval Medina (São Paulo: Prumo, 2012).
} 
Sacramento. Depois, próximo ao Mambituba, buscando a subida da serra, em direção a Sorocaba. Por ali, a partir de Laguna, seguirão as tropas de gado que, sobretudo no século XVIII, com a descoberta das minas de ouro, no interior das Gerais, tornam-se absolutamente necessárias para a manutenção daquelas populações ilhadas no interior das montanhas, na azáfama das catas auríferas.

Cristóvão Pereira, para a consecução de seu projeto, valeu-se originalmente do roteiro de Domingos da Figueira, Como viajar, por terra, da Colônia do Sacramento a Laguna, de 17036. Entre 1727 e 1735, ele abre variantes do caminho principal, melhorando-os sempre, de modo a viabilizar o transporte de numerosas tropas, desde o Rio Grande, até São Paulo e, dali, para as minas. Assim, quando os portugueses decidem, nas negociações que resultam no Tratado de Madrid, reivindicar os territórios já então ocupados e que se estendem da Laguna à Colônia do Sacramento, têm o que negociar com os espanhóis. Sabemos que Portugal prefere recuar, fisicamente, garantindo conquistas retiradas aos direitos espanhóis, fixando suas posses até a barra do Chuí e dali, em direção noroeste, até a região missioneira, de onde são expulsos os jesuítas e seus indígenas ${ }^{7}$.

A decisão parecia agradar a ambas as coroas: Madrid via-se livre da pressão da Colônia de Sacramento sobre Buenos Aires e Lisboa desfazia-se das ocupações jesuíticas do planalto, que de certo modo lhe ficavam às costas $\mathrm{e}$ sempre poderiam colocar em risco o desenvolvimento daqueles territórios mais próximos ao oceano. É que eles saíam das planícies do Chuí, subiam as encostas da serra Geral e se espalhavam pelo planalto que se estendia de leste a oeste da região, pela metade norte do atual estado do Rio Grande do Sul. Salvo a interrupção parcial do Rio Pelotas, continuavam pelo estado de Santa Catarina, em direção ao norte, o que facilitava o comércio nascente, mas lucrativo, que levava milhares de cabeças de gado alçado, desde o sul até os territórios auríferos, com grandes ganhos para os mercadores e a própria coroa portuguesa, que sobre essas atividades exercia cuidadoso controle e taxação eficiente, com vários pontos de contagem e cobrança de impostos.

No que toca ao planalto, a região experimentou forte desenvolvimento e assim se apresenta hoje em dia. Quanto ao litoral, aberta a rota alternativa da serra, que saía de Rio Pardo, passava por Porto Alegre e se dirigia a Lages, dali seguindo diretamente para Sorocaba, involuiu, perdeu população e viu-se praticamente esquecida, situação que remanesce em parte ainda hoje. A região intermediária, formada justamente pelas escarpas da serra, perdeu seu valor econômico e praticamente foi esquecida. Só ao final do século XX ela foi redescoberta e valorizada, ainda sob uma perspectiva econômica, desta vez enquanto via de desenvolvimento turístico e de transporte ${ }^{8}$. É desta esquecida e pouco conhecida região que Noite de reis se ocupa ${ }^{9}$.

Independentemente de sua qualidade literária, Noite de reis sanou uma ausência inexplicável da geografia literária brasileira e sul-rio-grandense: sua ação se passa exatamente nesta região de passagem, decorrendo nas fímbrias do planalto que termina nas escarpas e chega até o litoral. Deve-se lembrar que o texto ficcional pioneiro que abordava o litoral sul-rio-grandense é o romance $O$ corsário, de Caldre e Fião, editado em $1851^{10}$, mas que se limitou à faixa litorânea. Também este texto, produzido sob a perspectiva romântica do século XIX, andou desaparecido e esquecido, sendo, contudo, justamente recuperado e valorizado a partir de Guilhermino César (1956), em sua História da literatura do Rio Grande do Sul. No caso das escarpas da serra Geral, contudo, praticamente nada se tinha de documentação literária, até a edição, em 1935, do texto de que ora se ocupa este artigo. 678910

O Instituto Brasileiro de Geografia e Estatística (IBGE, 2006) vem desenvolvendo, desde 2006, um excelente projeto em torno do que denomina geografia literária do país. Esta obra procura desenvolver um mapeamento geográfico do Brasil a partir de sua literatura. Mas, por força de seu próprio projeto, pioneiro, ainda é muito generalista. No caso do Rio Grande do Sul, enfocado em volume já editado, vê-se que se escolheu a região das Missões, da campanha e das colônias ${ }^{11}$. Graças a esse aspecto relativamente macroscópico da obra, muita coisa, assim, fica de fora. Essa lacuna pode e deve ser gradualmente preenchida, desde que se busque descobrir, organizar, estudar e valorizar a produção literária, muitas vezes existente, mas perdida ou desconhecida, como ocorre com Noite de reis. Esta obra, denominada por seu autor como narrativa histórica, pretende desenvolver um acontecimento real, mesclando história e ficção, com isso preenchendo, seu autor, os vazios deixados pela memória dos eventos ocorridos. Trata-se da história de Baiano Candinho, quem o autor confessa não ter conhecido,

6 O documento encontra-se transcrito em CÉSAR, Guilhermino (Org.). Primeiros cronistas do Rio Grande do Sul (1605-1801). Porto Alegre: EDUFRGS, 1981, p. 55 e seguintes.

7 São os chamados tratados de Madrid e de Santo Ildefonso, respectivamente, dos anos de 1750 e de 1777 .

8 Ao longo de mais de duas décadas, buscou-se concretizar a construção de uma estrada segura e rápida, o que, enfim, foi alcançado com a inauguração da RS 153, em 2006, também chamada Estrada do Sol, que corre de oeste para leste, desde a região missioneira até a orla marítima, numa extensão de centenas de quilômetros, cortando as íngremes escarpas e facilitando o transporte e a locomoção.

9 De Manoel Fernandes BASTOS, editado em Porto Alegre, pela Globo, em 1935. A segunda edição, revisada e atualizada, foi publicada pela Evangraf, em Porto Alegre, em 2007.

${ }^{10}$ De José Antonio do Vale CALDRE E FIÃO. Editado em Porto Alegre, pela Movimento, em 1979.

${ }^{11}$ Refere-se às regiões ocupadas pelos colonizadores alemães e italianos aqui advindos a partir de 1824 e de 1875 , respectivamente. 
"mas dele ouvi histórias interessantes" (BASTOS, 1935, p. 23) ${ }^{12}$. Baiano Candinho, assim apelidado, era, na verdade, Martinho Pereira dos Santos que, junto a outros companheiros, desertara da Guerra do Paraguai e chegara àquele território perdido do Rio Grande do Sul, esperando que ali ninguém os conhecesse e assim pudessem recomeçar a vida. Adotou o nome de Cândido Alves da Silveira e, mais tarde, seria mais conhecido como "Baiano Candinho" (BASTOS, 1953, p. 33), considerado perigoso bandido e como tal devidamente executado, ou assassinado, como parece sugerir o autor da narrativa, em seu desfecho.

Manoel Estevão Fernandes Bastos, o autor do texto, nasceu em 1885, em Porto Alegre, filho de comerciantes. Órfão ainda menino, foi entregue aos cuidados de sacerdotes católicos. Casou-se em 1905, aos 21 anos de idade, e desempenhou múltiplas funções públicas, começando por ser amanuense na delegacia de polícia de Osório. Passou a exercer a advocacia, conforme a legislação então vigente, mesmo que sem a formação universitária de Direito, chegando a inscrever-se na Ordem dos Advogados do Brasil. Foi intendente municipal por três vezes, a primeira das quais em 1912, aos 27 anos de idade, e a última em 1928. Em 1933 é admitido como membro do Instituto Histórico e Geográfico do Rio Grande do Sul, com o qual colaborou assiduamente. Localizou e entregou ao IHGRGS documentos importantes da história regional, como os originais de titulação da Sesmaria das Conchas, de 1732, confirmada por Dom João V, em 1734, e que se constitui, certamente, na primeira concessão documentada de terras em solo sul-rio-grandense. Escreveu algumas peças teatrais, conforme registro de Pedro Leite Villas-Bôas (1991), mas não localizadas até hoje. Colaborou com jornais da região e em A Federação, do Partido Republicano RioGrandense, de Julio de Castilhos. Elaborou, também, uma obra sobre a Fundação da colônia de Três Forquilhas (1926), desenvolveu ensaios de folclore, além de outros textos variados. Importante, ainda, é seu $A$ estrada de Laguna ao Rio Grande, de 1937. Faleceu aos 53 anos de idade, em Porto Alegre, em 1938 ${ }^{13}$. Noite de reis teve uma primeira edição em 1935, por conta das Oficinas Gráficas da Livraria do Globo, da empresa Barcellos, Bertaso \& Cia., de Porto Alegre. A capa e a folha de rosto

\footnotetext{
${ }^{12}$ Esta assertiva empresta ao texto características da antiga crônica, como tal a conhecemos nos textos primitivos de Chrétiens de Troyes e outros escritores medievais. Como avanço do texto, contudo, verificamos que o autor aproxima-se mais de elementos históricos, transformando seu trabalho numa espécie de narrativa de fundo histórico, claramente situado entre o período de setembro de 1871 (p. 33) e 6 de janeiro de 1898 (p.255), quando se dá o desfecho da trama.

13 Os dados aqui sintetizados foram retirados de uma apresentação que consta da segunda edição da obra aqui referida e que têm, como fontes originais, SILVA, Marina Raymundo. Biografia dos intendentes e prefeitos do município de Osório. Osório: Datilograph, 1995, p. 22-24.
}

estão reproduzidas em fac-símiles estampados na segunda edição (2007). Mas estas reproduções não ajudam a saber se aquela foi uma edição financiada pelo próprio autor ou teve a aprovação do então diretor da editora.

Tentemos esclarecer:

Em 1935, a livraria do Globo publicou, de Erico Verissimo, Caminhos cruzados. Quando, no final do ano, Erico recebeu da Academia Brasileira de Letras o prêmio Graça Aranha, ao saber das notícias José Bertaso pai esboçou um sorriso e cumprimentou, satisfeito, o assistente do seu filho mais velho (BERTASO, 1993, p. 17).

\section{Eis o depoimento do próprio Erico Verissimo:}

\begin{abstract}
Em princípios do ano de 1931 Mansueto Bernardi embarcou para o Rio, onde foi imprimir dinheiro e cunhar moedas para a nação. Henrique Bertaso tomou conta da Seção editora e eu da Revista do Globo. Cada qual, enfim, seguiu o seu caminho e cuidou de sua vida (VERISSIMO, 1973b, p. 21-23).
\end{abstract}

$\mathrm{Na}$ mesma obra, Verissimo menciona diferentes obras editadas por Bertaso (1973b, p. 35), sem qualquer alusão ao trabalho de 1935. Sabe-se, contudo, pelo próprio escritor, que um dia, "não saberia dizer exatamente em que ano" (1935b, p. 40), ele foi convidado por Bertaso a colaborar com a editora. Em oito meses, Verissimo teria traduzido e editado Contraponto, de Aldous Huxley, "publicado em 1935" (1973b, p. 41). Em 1935 também nasce Clarissa. Henrique Bertaso mora no mesmo prédio em que o escritor vive, um andar abaixo. As duas famílias têm relações muito estreitas (1973b, p. 48-49). Erico publicaria, ainda em 1935, Caminhos cruzados. Nenhuma alusão ao livro de Fernandes Bastos.

Erico Verissimo assumira a Revista do Globo em 1932 (cf. BATISTA, 2008). Sua aproximação com Henrique Bertaso ocorre a partir de 1931(VERISSIMO, $1973 b$, p. 249). No ano de 1935, que interessa a esta pesquisa, Erico Verissimo publicaria ainda $A$ vida de Joana D'Arc. Lemos, nas memórias de Erico:
Na Livraria do Globo minha situação havia mudado. Henrique Bertaso convidara-me para assumir as fun- ções de conselheiro literário da sua editora, à qual desejava dar novo impulso. Aceitei o cargo e comecei ma trabalhar, ajudando Henrique a organizar progra- mas editoriais, selecionar obras estrangeiras para traduzir, descobrir os tradutores adequados, fiscalizar a tradução, estudar o formato do volume, escolher o desenho da capa, o tipo da composição do texto, o título definitivo em português e finalmente planejar o lançamento do livro (VERISSIMO, 1973a, p. 263).

Pode-se deduzir que a principal tarefa de Veríssimo voltava-se para as traduções. Portanto, a decisão - co- 
mercial ou literária - de publicar o texto de Fernandes Bastos foi de Henrique Bertaso: afinal, Bastos fora um prefeito (intendente) e incluía-se, naquele momento, entre os membros do Instituto Histórico e Geográfico do Rio Grande do Sul. Por outro lado, já editara outros trabalhos de cunho historiográfico e seu texto colocava-se enquanto uma narrativa histórica ${ }^{14}$. É evidente que ter uma obra editada pela Globo significava certo aval e pressuposto de qualidade.

Desde logo, o autor delimita seu campo de atuação. Para além da referência a uma narrativa histórica, já mencionada, na introdução de seu texto Bastos esclarece não se tratar de obra de ficção (1935, p. 23), acrescentando não ter conhecido o principal personagem de sua narrativa. Mas é, certamente, na escolha da epígrafe da obra, do poeta francês Alphonse de Lamartine, que o autor esclarece seu objetivo: "Nem sempre o sangue derramado grita terror e piedade, mas também lição e exemplo aos homens".

De fato, o enredo pretende reproduzir com veracidade a vida da personagem. Necessita, contudo, do preenchimento dos vazios que envolvem alguns desses acontecimentos. É evidente a preocupação com a recriação dos fatos e de vinculação dos mesmos aos episódios históricos que envolvem a personagem: a proclamação da república; a ascensão do Partido Republicano RioGrandense e de seu líder, Júlio de Castilhos, bem como as repercussões que tudo isso provoca, até mesmo nos mais recônditos lugares da província, como a Vila de Conceição do Arroio e a localidade de Três Forquilhas: cite-se, especialmente, o governicho de 1891 e a revolução de 1893. A ação dramática se encerra com o assassinato de Candinho Baiano, na noite de 6 de janeiro de 1898 (o que empresta o título à obra). Com isso, encontramos um gênero híbrido: não é exatamente, como seu autor pretende, apenas uma narrativa histórica, mas uma tentativa de estudo psicológico da personagem, que se divide, desde logo, entre os bons sentimentos de uma vida pacata e vinculada ao trabalho de peão de estância e de agricultor, que busca ter seu próprio chão e cuidar de sua família e, de outro lado, certo fatalismo típico da estética romântica, em que a personagem se debate entre o bem e o mal, acabando por naufragar ou sendo traída por aqueles que a rodeiam: neste caso, ambos os acontecimentos terminam por provocar a morte de Baiano.

O trabalho acaba não se definindo nem por um nem por outro caminho. Bastos evidencia ser um historiador preocupado com a fidelidade aos fatos: as referências que apresenta na obra comprovam isso. Ao mesmo tempo, mostra ter certa inclinação de ficcionista: o final do texto, por exemplo, é muito bem realizado, quando se antecipa a morte da personagem e, ao mesmo tempo, sugere-se a

\footnotetext{
$\overline{14}$ Conforme a capa da publicação e sua folha de rosto.
}

transformação da mesma numa espécie de legenda local e/ou regional (capítulos XXXVI a XXXVIII). Ao mesmo tempo, o autor paga certo preço ao princípio motivador que o teria levado a idealizar a narrativa: concretizar um texto exemplar, capaz de mostrar o quanto o crime é pernicioso a seu próprio autor. Isso se evidencia especialmente nesta espécie de determinismo e de antecipação das ações que caracterizam a narrativa. É certo que, ao começar a escrever, o autor sabe, antecipadamente, o que ocorreu: Baiano Candinho acabou morto, em sua própria casa, traído por aqueles que lhe eram mais próximos e nos quais ele depositava forte confiança.

$\mathrm{Ou}$ seja, a narrativa se constitui numa espécie de analepse a respeito de uma personagem cujo fim o narrador conhece antecipadamente. Aqui, talvez, resida uma das novidades do texto. Mas sua estrutura paga tributo à tradição literária do folhetim: desde o início do texto, também ao leitor é dado antecipadamente a informação de que a personagem morrera: melhor, confronta-se permanentemente a expectativa da personagem, que naturalmente desconhece sua sorte futura, com o conhecimento que dela tem o narrador e, através dele, o leitor: "E era este o doce pensamento que afagava a alma de Candinho naquela hora. Para aquele lugar, sem dúvida, fora o dedo de Deus que os guiara. Assim ainda pensava ele" (1935, p. 43, grifo nosso), ao que se acrescenta, no parágrafo seguinte: "E o destino humano escrevia naquele momento, sobre a fronte do mais moço daqueles baianos, uma das suas sentenças inapeláveis" (1935, p. 43).

Recuando no tempo, o narrador recorda a formação da colônia e, mais que isso, o clima social daquela região, abandonada pelas autoridades e que se acostumara, por isso mesmo, a receber foragidos. Os moradores precisavam adaptar-se aos que chegavam, já que deles não tinham como se defender. E tratavam, assim, de tirar as vantagens possíveis dos advenientes. Havia, pois, certa flexibilidade moral na colônia, que precisava sobreviver. Por outro lado, os acontecimentos políticos levarão a região a uma espécie de dependência indefesa do jogo partidário: ora republicanos, ora federalistas comandavam a província. As autoridades se revezavam, mas isso não era garantia de uma justiça equilibrada, porque ela sempre estava dependente dos mandatários locais, sobretudo os proprietários rurais do planalto e dos comerciantes da planície que, numa ou noutra situação, acabavam por ditar a aplicação das leis segundo seus interesses. As próprias autoridades encarregadas dessa tarefa entenda-se, delegados civis e forças militares - dependiam de nomeações e, portanto, dos interesses políticopartidários que definiam os nomeados.

$\mathrm{O}$ fatalismo que marca a narrativa e de certo modo decide a sorte da personagem não advém apenas de um acaso irracional, mas das regras políticas e sociais esta- 
belecidas: "E quantas coisas já tinham ocorrido, encaminhando para o seu destino a vida daquele desertor...!", comenta o narrador $(1935$, p. 63$)$.

Candinho Baiano tenta sobreviver. Os grandes proprietários de terras vivem da exploração desses pobres coitados. Os comerciantes admitem a convivência, na medida em que não podem se defender. Mas uns e outros manobram segundo seus próprios interesses. Resta pouco espaço e opções aos marginalizados sociais, dentre os quais se colocam figuras como Baiano Candinho. Bandido para uns, sujeito simpático e prestativo para outros, gente como Baiano Candinho transita num espaço indefinido da legalidade, conforme os interesses do momento. Assim, Candinho pode ser considerado ladrão e bandido, sendo caçado por forças policiais, de que em geral consegue se livrar, como pode se tornar inclusive autoridade política e militar, no eclodir do governicho de 1891. De modo geral, contudo, é simplesmente desconsiderado, como reconhece o narrador. Neste sentido, o capítulo XXXIII é central na narrativa. Ele ecoa, desenvolve e aprofunda indagações éticas e morais da personagem, que se espalham ao longo do texto, mas que aqui se concentram, numa espécie de segundo movimento de passagem ${ }^{15}$ : Candinho, após os episódios de 1893, já viúvo e tendo decidido casar novamente, para poder criar os filhos pequenos, mostrase indefinido entre ajudar às novas autoridades e prender aqueles pequenos marginais ou simplesmente manter-se ligados a eles:

- Isso é ser covarde. Caboclo nunca deixa companheiro mal.

E Candinho chegou a envergonhar-se de si mesmo. Novamente imergia num passado que já ficava distante, mas cuja lembrança jamais se poderia apagar da sua memória. (...) Que lhe valeu? Quem lhe levantou o rancho onde se pode abrigar? Quem lhe derrubou a coivara e lhe fez as primeiras plantações? Quem esteve a seu lado com dedicação, proporcionando-lhe com que matar a fome da mulher e dos filhos?

Foram os bons amigos da colônia? Foram as autoridades?

(...)

E Candinho chorou. Chorou, como chorara muitas vezes em momentos amargos da sua vida infeliz. (...)

De um salto, Candinho esteve de pé, levando a mão à testa como se quisesse retirar da cabeça um grande peso.

Abrindo a porta do rancho, saiu à rua, e foi ao arroio próximo banhar os olhos, que ainda estavam úmidos de lágrimas, e refrescar a testa, que ainda queimava (1935, p. 239-240).

\footnotetext{
${ }^{15} \mathrm{O}$ primeiro ocorre quando a esposa é violentada sexualmente por um jovem fazendeiro, de passagem pela região em que vive Candinho, com sua família. A personagem, impossibilitada de uma vingança imediata da honra, como que atravessa o Rubicão e adere decisivamente à bandidagem, o que significa pequenos furtos de gado e alianças estratégicas com outros marginais locais, de modo a sobreviver.
}

A transcrição é longa, mas necessária: ela, de certo modo, caracteriza toda a narrativa e a define. $\mathrm{O}$ destino, contudo, como uma espécie de moira a que a personagem não tem como se furtar, já traçou sua vida. Ainda que emocionalmente a personagem evidencie uma tendência positiva, o enredamento dos fios de sua vida e das vidas que se encontram a seu redor leva-o, obrigatoriamente, a ações que, embora ele renegue, não as pode deixar de realizar.

Os episódios neste sentido se sucedem. Quando de seu casamento com Maria Witt, decisão, afinal, positiva, pois se poderia pensar que, com isso, Candinho poderia fixar sua casa e desenvolver a família, o capítulo que narra tal acontecimento, contudo, assim se conclui:

$$
\begin{aligned}
& \text { E uma ave noturna soltou um pio agoureiro na caneleira } \\
& \text { desgalhada que ficava nos fundos do engenho. Mas } \\
& \text { ninguém ouviu. } \\
& \text { Naquela casa todos dormiam àquela hora (1935, p. } 72) \text {. }
\end{aligned}
$$

As personagens desconhecem o alerta que, no entanto, é compreendido pelo narrador, que se apressa a transmiti-lo ao leitor. Em outra passagem, Candinho, tentando distanciar-se dos comparsas e do crime, muda sua residência, subindo a serra, num de seus inúmeros movimentos de idas e vindas:

E Candinho, que tudo fizera para se afastar daquele homem, mal podia pensar o que essa nova aproximação lhe reservava para muitos breves dias. E muito menos podia imaginar, despreocupado como estava naquele recanto solitário das serra, que se encontrava num dos momentos da vida em que se resolve o destino de um homem.

Assim é a vida, quando a fatalidade o quer (1935, p. 95).

Por isso mesmo, indaga-se o narrador, em certo momento, como que se dirigindo ao leitor:

Poderá esse homem continuar a viver, como tanto queria, dentro do trabalho e da honradez, ou a fatalidade cruel o arrastará também para as correrias e para o crime? (1935, p. 104)

Reitera o narrador, mais adiante, como que a eximir a personagem de alguma responsabilidade:

A desgraça, entretanto, parece que o perseguia inexoravelmente. Rememorava os anos passados. Quis ser bom, quis trabalhar, mas ela não consentiu que ficasse lá naquela colônia onde, ao chegar, maltrapilho e faminto, pensou ter encontrado a terra prometida (1935, p. 114).

Daí se segue uma observação, em meio ao texto, emprestada a uma personagem anônima, um "mulatinho que morava lá para o lado do 'Chapéu' e que se conservara durante todo o tempo recostado ao balcão": 
- E sabem de uma coisa? Ninguém brinque com o 'Seu Candinho'. A minha mãe já disse que tirou a sorte dele. Ele ainda vai botar tudo debaixo do braço. E para prender ou para matar só se fizerem traição bem feita. De cara a cara é bobage. Ninguém pode com ele (1935, p. 146).

De fato, como depois se saberá, com as mudanças dos ventos políticos e partidários, Candinho chega a ser Major e, em seguida, Coronel Candinho nas forças liberais que se opõem a Julio de Castilhos. No entanto, assim como ocorre com o major Azevedo, assassinado pelos asseclas republicanos, com a queda dos liberais, Baiano Candinho tem sua sorte decidida. A tragédia se desenha pouco antes do 6 de janeiro de 1898. Com a chegada da noite de reis (referência que dá nome ao livro ${ }^{16}$ ), a casa de Baiano Candinho é visitada: a própria personagem abre a porta e é imediatamente alvejada:

E no interior daquele rancho tomaram-se posições, e trocaram-se olhares que diziam um mundo de coisas, que o dono da casa não podia compreender.

Como havia de compreender?

Aquela noite não era Noite de Reis, noite de folgança, noite de alegria, noite de paz, noite de reconciliação?

Aos maiores bandidos concediam-se tréguas, para que eles também pudessem render o culto de sua veneração àquele menino que nasceu pelo Natal, alvoroçando toda a cristandade.

Isso era de todos os tempos.

(...) Só ele, Candinho, estaria condenado a uma sentença tão atroz: morrer nas mãos de romeiros que lhe batiam à porta para lhe anunciarem, em cânticos de sublime misticismo, as novas do Evangelho, a reconciliação de Deus com os pecadores e o reinado da paz entre os homens!?... (1935, p. 262-263).

Fatalidade e destino radicalmente executados: é na noite em que se comemora a chegada dos reis magos, segundo a tradição cristã, com seus presentes para o menino Jesus, símbolo de vida e de redenção, que Baiano Candinho é assassinado. Seus executores, em ironia atroz, subvertem o sentido da festa: contando com a confiança da vítima, trazem-lhe a morte. Completa-se, assim, a metáfora buscada pelo escritor e que, certamente, justificou sua realização literária: aos marginalizados a História não concede nem oportunidades, nem trégua. Assim, sua sorte é decidida pelos inimigos, por certo, mas com a decisiva participação daqueles que considera amigos ou, ao menos, parceiros.

\footnotetext{
${ }^{16}$ A noite de reis é tradição do ciclo natalino. Tem origem ibérica. No Rio Grande do Sul, um grupo de músicos e canta e toca, deslocando-se de casa em casa, sendo recebido com comidas e bebidas. Ler a respeito em: CÂMARA CASCUDO, Luis da. Dicionário do folclore brasileiro. Belo Horizonte: Itatiaia, 1984.
}

O romance não é literariamente bem realizado. Mas surpreende, a todo o momento, a força da narrativa, nem tanto pela qualidade da escrita do autor, como por suas convicções. Ele soube escolher passagens e contextos em que a figura contraditória de Baiano Candinho vai sendo apresentada ao leitor. Desse leitor, na verdade, não se espera nem apoio nem compreensão, mas, sim, aquilo que a epígrafe antecipara: que ele entenda a moralidade do relato.

\section{Referências}

BASTOS, Manoel Estevão Fernandes. Noite de reis. Porto Alegre: Globo, 1935.

BATISTA, Karina Ribeiro. A trajetória da Editora Globo e sua inserção no campo literário brasileiro nas décadas de 1930 e 1940. Porto Alegre: PUCRS, 2008.

BERTASO, José Otávio. A Globo da Rua da Praia. Porto Alegre: 1993.

CALDRE E FIÃO, José Antonio do Vale. O corsário. Porto Alegre: Movimento, 1979.

CÉSAR, Guilhermino (Org.). Primeiros cronistas do Rio Grande do Sul (1605-1801). Porto Alegre: EDUFRGS, 1981.

CÉSAR, Guilhermino. História do Rio Grande do Sul: período colonial. Porto Alegre: Globo, 1970.

HOHLFELDT, Antonio; TARRAGÓ, Júlia Pereira. Síntese da imprensa periódica na província de Cabo Verde. Apresentado no GP História do Jornalismo, do XXXIV Congresso Brasileiro de Ciências da Comunicação, Recife, Universidade Católica de Pernambuco, promovido pela INTERCOM - Sociedade Brasileira de Estudos Interdisciplinares da Comunicação, $1^{\circ}$ a 7 de setembro de 2011 .

IBGE. Atlas das representações literárias de regiões brasileiras: Brasil Meridional. Rio de Janeiro: IBGE, 2006.

MEDINA, Sinval. O cavaleiro da Terra de Ninguém. São Paulo: Prumo, 2012

PESAVENTO, Sandra Jatahy. História do Rio Grande do Sul. Porto Alegre: Mercado Aberto, 1985.

SILVA, Marina Raymundo. Biografia dos intendentes e prefeitos do município de Osório. Osório: Datilograph, 1995.

SOUSA, Pero Lopes. Diário da navegação de Pêro Lopes de Sousa (1530-1532). In: CORDEIRO, J. P. Leite; ABREU, Capistrano de (Org.). Cadernos de história, v. 1. São Paulo: Parma, 1979.

VERISSIMO, Erico. Solo de clarineta, Porto Alegre, Globo. 1973.

VERISSIMO, Erico. Um certo Henrique Bertaso. Porto Alegre: Globo, 1973.

VILLAS-BÔAS, Pedro Leite. Dicionário bibliográfico gaúcho. Porto Alegre: EST, 1991.

Recebido: 13 de abril de 2013

Aprovado: 18 de setembro de 2013

Contato: a hohlfeldt@yahoo.com.br; anamunari@terra.com.br 